\title{
Exudative Retinal Detachment Treatment in a Patient with Thrombotic Thrombocytopenic Purpura
}

\author{
Magali Sampo ${ }^{a}$ Gaëlle Ho Wang Yin ${ }^{a}$ Louis Hoffart ${ }^{a, b}$ Danièle Denis \\ Vincent Soler $^{\mathrm{d}}$ Frédéric Matonti ${ }^{\mathrm{b}, \mathrm{c}}$

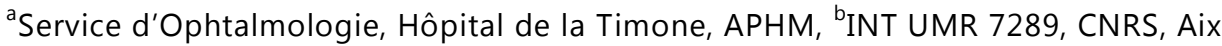 \\ Marseille Université, and 'Service d'Ophtalmologie, Hôpital Nord, APHM, Marseille, and \\ ${ }^{d}$ Service d'Ophtalmologie, Pôle Céphalique, Hôpital Pierre-Paul Riquet, Toulouse, France
}

\section{Key Words}

Exudative retinal detachment $\cdot$ Thrombotic thrombocytopenic purpura $\cdot$ Plasmapheresis

\begin{abstract}
Purpose: We report a case of unilateral exudative retinal detachment in a patient with thrombotic thrombocytopenic purpura (TTP), without associated hypertension, successfully treated with plasmapheresis. Case Report: A 46-year-old woman with a medical history of TTP presented with unilateral exudative retinal detachment. Biological and radiological assessment eliminated other causes of exudative retinal detachment, including hypertension. Plasma exchange was performed, followed by a rapid improvement in visual acuity and total disappearance of serous detachment. Conclusion: Exudative unilateral retinal detachment is a rare complication of TTP and can be successfully treated by plasma exchange.
\end{abstract}

(C) 2016 The Author(s)

Published by S. Karger AG, Basel

\section{Introduction}

Thrombotic thrombocytopenic purpura (TTP) is a rare but life-threatening thrombotic microangiopathy (2.9 cases/million/year) which can affect multiple organs. The clinical features of TTP are due to recurrent episodes of microangiopathic hemolytic anemia and thrombocytopenia. TTP is caused by the formation of thrombi within the microvasculature

\section{KARGER}

Magali Sampo

Service d'Ophtalmologie, Hôpital de la Timone, APHM

264 rue saint-Pierre

FR-13005 Marseille (France)

E-Mail magali.sampo@ap-hm.fr 
Sampo et al.: Exudative Retinal Detachment Treatment in a Patient with Thrombotic Thrombocytopenic Purpura

due to the inhibition of a disintegrin and metalloprotease with a thrombospondin type I domain 13 (ADAMTS13) [1]. These thrombi are composed of platelets and ultralarge von Willebrand factor (ULVWF) multimers. These multimers of VWF induce platelet aggregation and, normally, are cleaved by ADAMTS13. Acquired TTP is associated with severe VWF cleaving deficiency caused by IgG autoantibodies that inhibit ADAMTS13, which results in excessive platelet aggregation.

Exudative retinal detachment is a rare ocular complication in patients with TTP. Most of the cases are bilateral and associated with hypertension. Herein, we report a case of unilateral exudative retinal detachment without concomitant hypertension successfully treated by plasmapheresis.

\section{Case Report}

A 46-year-old North African woman presented with a sudden loss of vision. She had a medical history of TTP diagnosed 8 years ago and a severe left amblyopia since childhood (unknown etiology).

Initial ophthalmologic examination found a visual acuity limited to hand movement in the right eye and light perception in the left eye. Slit-lamp examination of the anterior segment and intraocular pressure were normal. Fundus examination showed an exudative retinal detachment of the posterior pole in the right eye, without uveitis or papillary edema (fig. 1a). The retinal vessels were normal. In the left eye, fundus examination found chorioretinitis scars and optic atrophy. Spectral-domain optical coherence tomography (SD-OCT) confirmed the exudative retinal detachment with intraretinal cysts in the right eye (fig. 1b) and choroidal atrophy in the left eye. Fluorescein and indocyanine angiography found a delayed choroidal perfusion (fig. 2).

At diagnosis, laboratory studies showed a thrombocytopenia with platelet count at $30,000 / \mu \mathrm{l}$ with a mild anemia; the hemoglobin level was $10 \mathrm{~g} / \mathrm{dl}$. The lactate dehydrogenase level was increased $(2,961 \mathrm{IU} / \mathrm{l})$. ADAMTS13 activity was undetectable $(<5 \%$ of normal activity), with positive anti-ADAMTS13 antibodies. Serum creatinine and liver enzyme levels were normal. The $\beta$-hCG test was negative, and blood pressure was normal. She did not have neurologic or dermatologic symptoms.

Therefore, this exudative retinal detachment was supposed to be a complication of TTP. Plasma exchange treatment was performed (daily plasma exchange and additional treatment with corticoid starting 2 weeks after the beginning of the plasmapheresis). A few hours after the first plasmapheresis, the patient started to regain her sight, and 2 days after the first plasmapheresis, an improvement in visual acuity to $20 / 32$ in the right eye was observed. Fundus and SD-OCT found a total disappearance of the exudative retinal detachment (fig. 3a, b). However, ischemia sequels were present with pigmented retinal epithelium swelling (fig. 3c).

\section{Discussion}

Exudative retinal detachment is a rare but reported complication of TTP. However, most patients so far had a bilateral retinal exudative detachment. The only other case of unilateral exudative retinal detachment described was due to a retinal pigment epithelium tear [2]. In our patient, the unilateral involvement can be explained by the preexisting choroidal atrophy in the left eye. 
Sampo et al.: Exudative Retinal Detachment Treatment in a Patient with Thrombotic Thrombocytopenic Purpura

Exudative retinal detachment in TTP is usually associated with hypertension. In our patient, the blood pressure was normal, and there was no other sign of hypertensive retinopathy. Only 3 other cases unrelated to hypertension have been reported [2-4]. However, for 2 of the 3 cases, other risk factors for exudative retinal detachment were present, such as a postpartum context [3] or a retinal pigment epithelium tear [2]. This suggests that hypertension probably plays an important role in the development of exudative retinal detachment in TTP, but other factors remain to be identified.

Retinal exudative detachment in TTP is supposed to be caused by a disruption of the outer retinal blood barrier and a choroidal ischemia. Microthrombi are formed by platelet aggregation, which leads to vessel occlusions that may occur in the choroidal network. Excessive platelet aggregation mediated by ULVWF multimers is caused by a failure of the proteolytic action of the metalloproteinase ADAMTS13 [5]. The plasma ADAMTS13 activity level is $<5 \%$ in acute TTP [6], as in our patient.

In case of exudative retinal detachment caused by TTP, the main treatment is plasmapheresis [7]. The efficacy of plasma exchange compared with plasma infusion was confirmed in a randomized trial [8], and it is assumed that patients with high titers of antibodies require plasmapheresis to supply a normal protease ADAMTS13 level and remove the inhibitory antibodies (anti-ADAMTS13). This enables cleavage of ULVWF multimers and reduces excessive platelet aggregation.

Although plasmapheresis has greatly improved the mortality of TTP, it is still a potentially lethal disease [9]; therefore, it is necessary to avoid any therapeutic delay. Exudative retinal detachment can be the first manifestation of TTP, and ophthalmologists should be aware of this.

\section{Statement of Ethics}

The authors have no ethical conflicts to disclose.

\section{Disclosure Statement}

The authors declare that they have no conflicts of interest.

\section{References}

1 George JN, Nester CM: Syndromes of thrombotic microangiopathy. N Engl J Med 2014;371:654-666.

2 Harris JA, Friedman MT, Varma M: Unilateral serous retinal detachment in a patient with thrombotic thrombocytopenic purpura. J Clin Apher 2008;23:116-117.

-3 Titah C, Abisror N, Affortit A, Coppo P: Bilateral serous detachment of retina: an unusual mode of revelation of thrombotic thrombocytopenic purpura of favorable outcome with plasma exchange. Graefes Arch Clin Exp Ophthalmol 2014;252:181-183.

-4 Wyszynski RE, Frank KE, Grossniklaus HE: Bilateral retinal detachments in thrombotic thrombocytopenic purpura. Graefes Arch Clin Exp Ophthalmol 1988;226:501-504.

$\checkmark 5$ Sadler JE, Moake JL, Miyata T, George JN: Recent advances in thrombotic thrombocytopenic purpura. Hematology Am Soc Hematol Educ Program 2004:407-423.

6 Tsai HM: Pathophysiology of thrombotic thrombocytopenic purpura. Int J Hematol 2010;91:1-19.

7 Nanayakkara P, Gans RO, Reichert-Thoen J, ter Wee PM: Serous retinal detachment as an early presentation of thrombotic thrombocytopenic purpura. Eur J Intern Med 2000;11:286-288.

-8 Rock GA, Shumak KH, Buskard NA, Blanchette VS, Kelton JG, Nair RC, Spasoff RA: Comparison of plasma exchange with plasma infusion in the treatment of thrombotic thrombocytopenic purpura. Canadian Apheresis Study Group. N Engl J Med 1991;325:393-397. 
Case Reports in

Ophthalmology

\begin{tabular}{l|l}
\hline Case Rep Ophthalmol 2016;7:90-95 \\
\hline DOI: 10.1159/000444291 & $\begin{array}{l}\text { ○ } 2016 \text { The Author(s). Published by S. Karger AG, Basel } \\
\text { www.karger.com/cop }\end{array}$ \\
\hline
\end{tabular}

Sampo et al.: Exudative Retinal Detachment Treatment in a Patient with Thrombotic Thrombocytopenic Purpura

-9 Hay-Smith G, Sagoo MS, Raina J: Fatal thrombotic thrombocytopenia purpura presenting with choroidal vasculopathy and serous retinal detachment. Eye 2006;20:982-984.
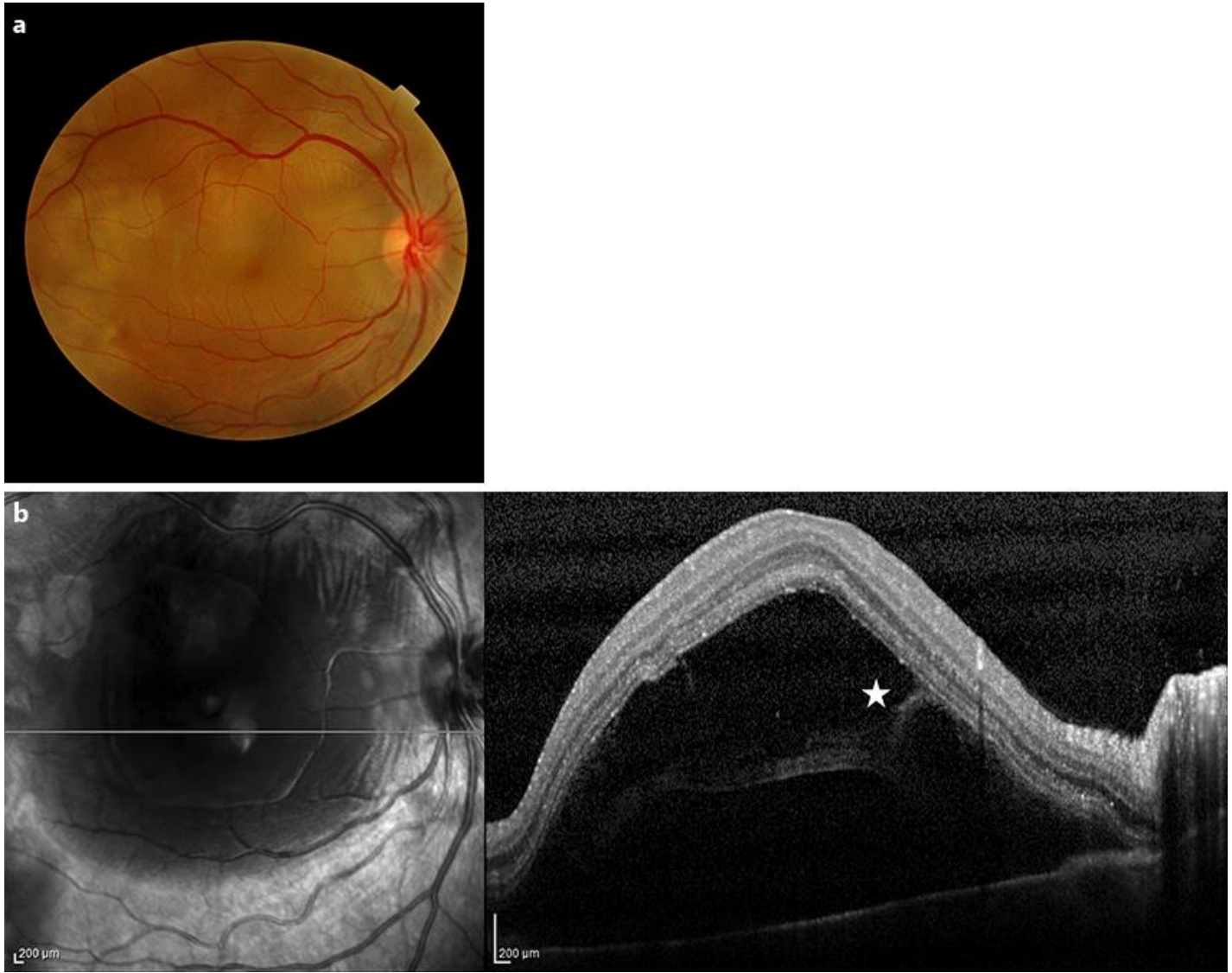

Fig. 1. a Right-eye fundus at the initial examination, showing an exudative retinal detachment. b SD-OCT scans of the right eye during the initial examination. SD-OCT scan displaying an exudative retinal detachment containing some hyperreflective membranous structures (star). 
Case Reports in

Ophthalmology
Case Rep Ophthalmol 2016;7:90-95

\begin{tabular}{|l|l} 
DOI: $10.1159 / 000444291$ & C 2016 The Author(s). Published by S. Karger AG, Basel
\end{tabular} www.karger.com/cop

Sampo et al.: Exudative Retinal Detachment Treatment in a Patient with Thrombotic Thrombocytopenic Purpura

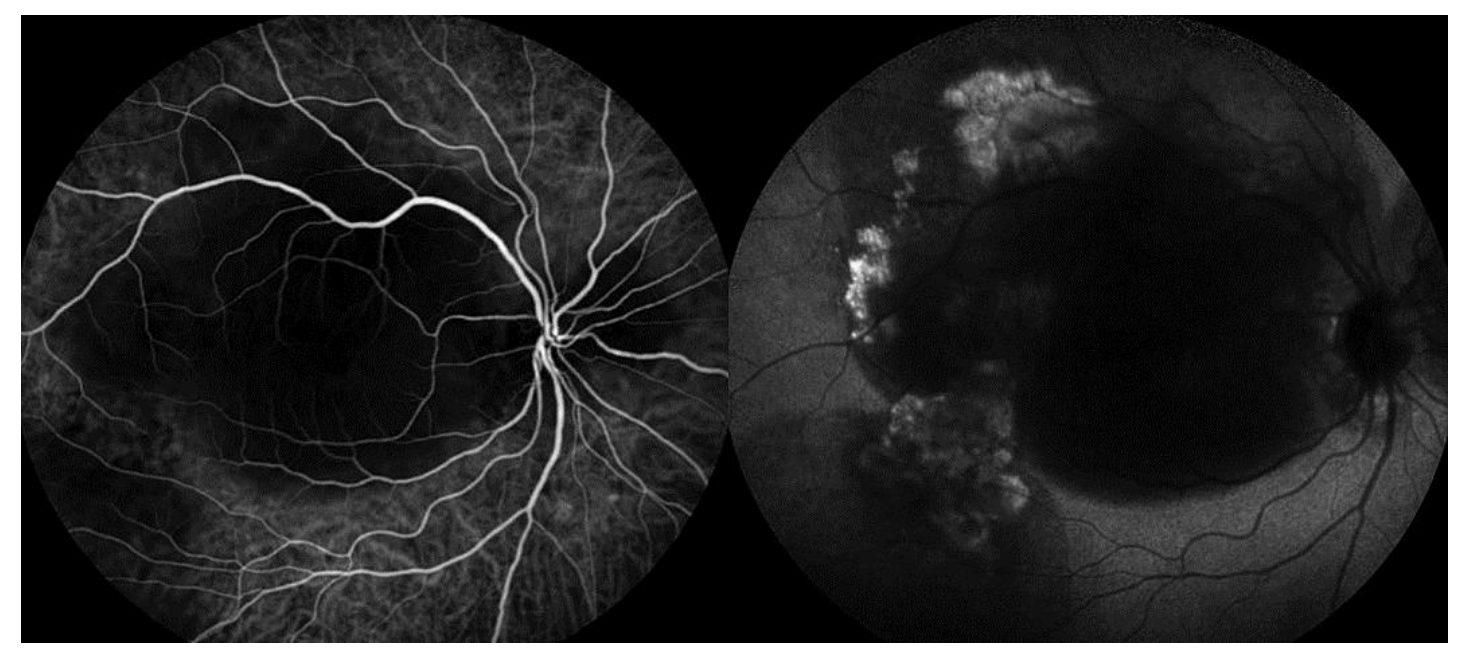

Fig. 2. Indocyanine green angiography showing irregular perfusion of the choroid. 
Case Reports in

Ophthalmology
Case Rep Ophthalmol 2016;7:90-95

\begin{tabular}{l|l}
\hline DOI: $10.1159 / 000444291$ & $\begin{array}{l}\text { C } 2016 \text { The Author(s). Published by S. Karger AG, Basel } \\
\text { www.karger.com/cop }\end{array}$
\end{tabular}
www.karger.com/cop

Sampo et al.: Exudative Retinal Detachment Treatment in a Patient with Thrombotic Thrombocytopenic Purpura
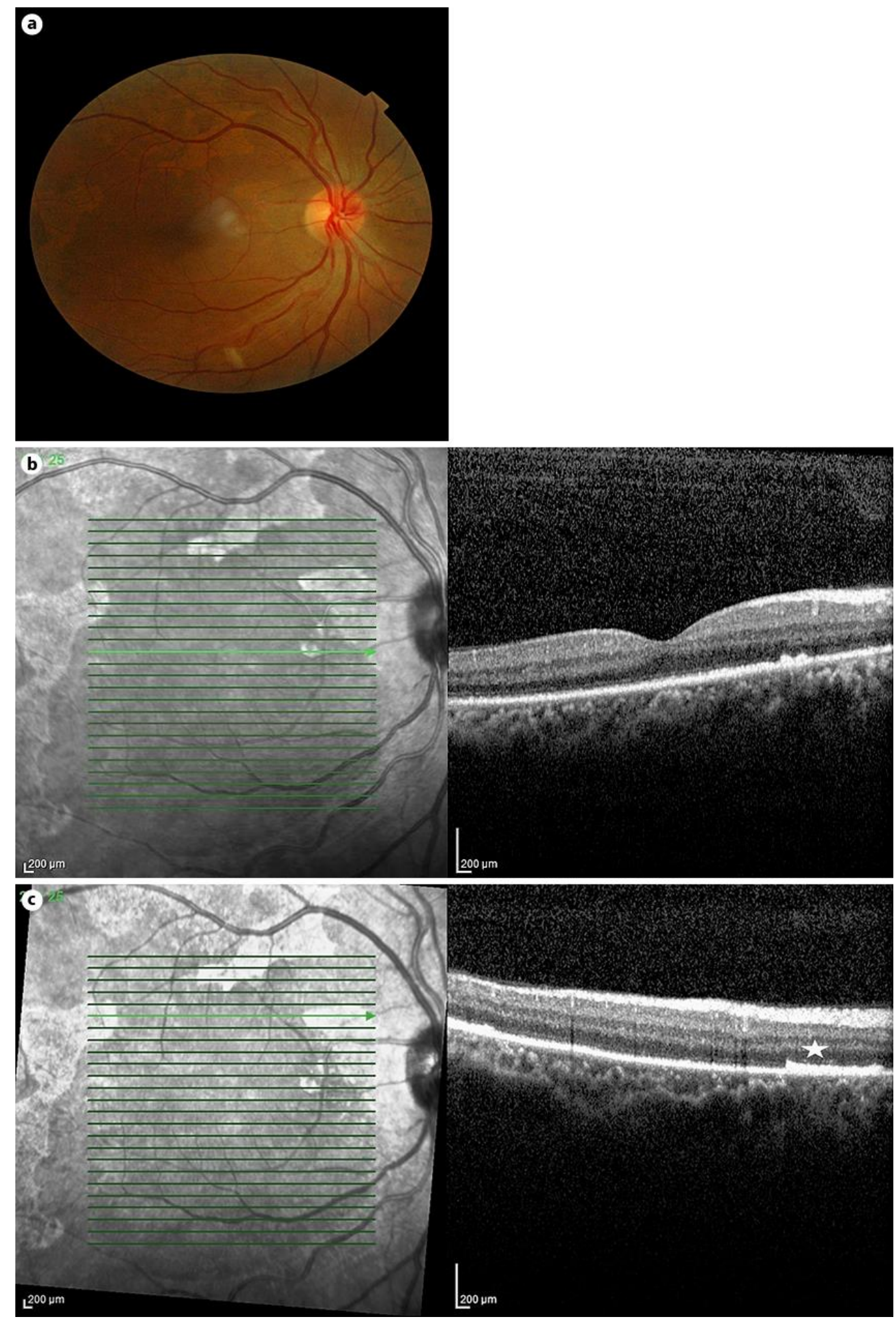

Fig. 3. a Right-eye fundus 2 days after plasmapheresis exchange, showing the disappearance of retinal detachment. b SD-OCT scans of the right eye 2 days after plasmapheresis exchange confirm the total disappearance of retinal detachment. c Ischemia sequel (b) with pigment epithelium swelling (star) on the SD-OCT scans after plasmapheresis. 